\title{
Kidney sales and the analogy with dangerous employment
}

\author{
Erik Malmqvist
}

Linköping University Post Print

Tweet

N.B.: When citing this work, cite the original article.

The original publication is available at www.springerlink.com:

Erik Malmqvist, Kidney sales and the analogy with dangerous employment, 2013, Health Care Analysis.

http://dx.doi.org/10.1007/s10728-013-0270-3

Copyright: Springer Verlag (Germany)

http://www.springerlink.com/?MUD=MP

Postprint available at: Linköping University Electronic Press

http://urn.kb.se/resolve?urn=urn:nbn:se:liu:diva-108337 


\title{
KIDNEY SALES AND THE ANALOGY WITH DANGEROUS EMPLOYMENT
}

\author{
Erik Malmqvist \\ Linköping University
}

This is a preprint version. Please cite the final version:

Malmqvist, E. "Kidney sales and the analogy with dangerous employment," Health Care Analysis (published online 27 December 2013, DOI: 10.1007/s10728-013-0270-3)

The final publication is available at link.springer.com.

\begin{abstract}
Proponents of permitting living kidney sales often argue as follows. Many jobs involve significant risks; people are and should be free to take these risks in exchange for money; the risks involved in giving up a kidney are no greater than the risks involved in acceptable hazardous jobs; so people should be free to give up a kidney for money, too. This paper examines this frequently invoked but rarely analysed analogy. Two objections are raised. First, it is far from clear that kidney sales and dangerous jobs involve comparable risks on an appropriately broad comparison. Second, and more importantly, even if they do involve comparable risks it does not follow that kidney sales must be permitted because dangerous jobs are. The analogy assumes that kidney sales are banned for paternalistic reasons. But there may be other, non-paternalistic reasons for the ban. And paternalists, too, can consistently defend the ban even if kidney sales are no riskier than occupations that they find acceptable. Soft paternalists may want to protect would-be vendors from harms that they have not voluntarily chosen. Egalitarian hard paternalists may want to protect already badly off vendors from further worsening their situation. For neither species of paternalist is the size of the risk prevented decisive. I conclude that the analogy with dangerous jobs, while rhetorically powerful, pulls little real argumentative weight. Future debates on living kidney sales should therefore proceed without it.
\end{abstract}

Keywords: analogical reasoning, ethics, organ sales, paternalism, risks and benefits, transplantation 


\section{INTRODUCTION}

Here is a question that has engaged economists, philosophers, bioethicists and physicians for decades: if I want to sell one of my kidneys while I am alive, should I be allowed to do so? On the face of it, there seem to be strong reasons to think that I should. First, if the transaction is voluntary, then permitting it recognises my capacity to decide about my own life. Second, the transaction would make available a resource capable of saving or improving someone else's life. Third, assuming that the money is more valuable to me than the kidney - why else would I voluntarily agree to the exchange? - I too would benefit. Thus framed, kidney sales appear to fit comfortably within the larger class of voluntary, mutually beneficial transactions that liberal societies permit and indeed encourage.

No wonder, then, that one major line of argument for permitting kidney sales proceeds by likening them with other such transactions that are already permitted. The most common analogy is between selling a kidney and selling one's labour. For example, Cécile Fabre writes:

[I]f someone's interest in raising income by engaging in very risky activities such as being a full-time boxer or a building-site worker - is deemed important enough to confer on her the right to do so...there is no reason to deny her the right to make parts of her body available to others in exchange for money, even though she would incur similar risks in so doing (Fabre, 2006, p. 131).

Similarly, Stewart Cameron and Raymond Hoffenberg argue:

The actual risk of loss of life during donation of a kidney has been estimated to be approximately $0.03 \%$, which is considerably less than the risk associated with 
some paid occupations, for example, deep-sea diving, construction work, or mining...As we do not express many qualms about these, why do we about organ donation? Why should the risk be different because the donor is paid? (Cameron and Hoffenberg, 1999, p. 727)

The argument appears to go as follows. Many jobs involve significant risks; people are and should be free to take these risks in exchange for money; the risks involved in giving up a kidney are no greater than the risks involved in acceptable hazardous jobs; so people should be free to give up a kidney for money, too. In short, given that risk-taking for money is rightly permitted in one context it cannot consistently be prohibited in another context, if the risks are no greater there.

While frequently invoked in the debate, ${ }^{i}$ the analogy between kidney sales and hazardous jobs is seldom subject to systematic analysis. ${ }^{\text {ii }}$ My aim in this paper is to provide such an analysis. I will ask two questions. First, are the risks in dangerous jobs and kidney sales comparable? Second, if they are, does it matter? I shall suggest that the answer to the first question is much less straightforward than what is usually assumed. The second question is more important but less debated. My answer to that question will be that the hazardous job analogy does much less moral work than its proponents think. The analogy looks like a plausible objection to the ban on kidney sales because it is assumed that the ban is paternalistic: that it seeks to protect would-be vendors from harm. However, there may be other, non-paternalistic reasons for the ban. And even if its rationale is paternalistic, it need not be inconsistent with permitting equally risky or riskier occupations.

Why focus on hazardous jobs? Kidney sales proponents often compare such sales with other permitted but risky activities: unpaid kidney donation (Radcliffe-Richards, 1996, p. 386; Wilkinson, 2003, p. 108; Taylor, 2005, p. 137), paid participation in medical 
research (Dworkin, 1994, p. 157; Friedman, 2006, p. 747), and pastimes such as rock climbing and skiing (Radcliffe-Richards, 1996, p. 385; Savulescu, 2003, p. 139). However, the employment analogy merits special attention, partly because of its ubiquity in the debate, partly because it has more initial plausibility. The comparison with donation is open to the objection that gift exchanges and sales are morally different (Titmuss, 1970). The comparison with paid research participation will not convince those who doubt whether that activity itself should be permitted (McNeill, 1997). And risks are arguably more tolerable in activities highly valued for their own sake, such as dangerous pastimes, than in activities undertaken for instrumental reasons, such as selling a kidney (Taylor, 2005, pp. 122-125). If one wants to establish that kidney sales should be permitted, the best comparison is with hazardous activities that are and should be permitted and whose value is mainly instrumental. Not all risky jobs fit this description. Some are arguably either dangerous or degrading enough to warrant prohibition (think of sweatshop labour), or highly valued in themselves (think of professional sports). But other risky jobs do seem to be both rightly permitted and primarily instrumentally valued. Construction work and mining come to mind. To make the analogy as plausible as possible, I shall understand it as appealing to jobs like these.

\section{COMPARING RISKS}

\section{Risks and benefits}

In its simplest form, the analogy between selling a kidney and selling one's labour relies on a comparison of the mortality rates for nephrectomies and risky occupations (Cameron and Hoffenberg, 1999, p. 727; Wilkinson, 2003, p. 108). A common estimate for nephrectomies is about $0.03 \%$ (Matas et al., 2003; Segev et al. 2010), which is lower than or similar to the 
mortality rates among, for instance, fishermen $(0.116 \%)$, mining machine operators $(0.039 \%)$ and roofers $(0.032 \%)(B L S, 2011)$.

Such comparisons are much too simple. To begin with, the mortality rates are calculated over different time spans in the two contexts. The figure for nephrectomy captures the risk of dying during or soon before or after surgery (perioperative risk), while the employment figures capture the risk of dying over the course of a year. Risks calculated over different time spans are not straightforwardly comparable. Other things being equal, it is worse to face a specific risk of dying over a short period of time than facing it over a longer period (Horrobin 2005, p. 263).

But suppose the mortality rates for nephrectomies and dangerous occupations were recalculated so as to be comparable and still found to be roughly equal. Comparing the two figures would still not do the work that proponents of kidney sales want it to do. To see why, recall some basic points about the ethics of risk.

First, when we contemplate whether it is morally acceptable to expose someone else to a risk, or rational to run a risk ourselves, we are not only interested in the size of the risk. What we want to know is whether the risky course of action is expected to produce outcomes that make the risk worth taking. In short, risks have to be weighed against benefits (Hansson, 2004). Second, such weighing tends to be a complex task. A given course of action may involve several different harms and risks, and several different benefits and chances, all of which need to be included in a global assessment. Third, in some contexts it is assumed that risks to an individual can only be outweighed by benefits to that same individual; in other contexts it is assumed that risks to an individual should be weighed against the sum total of benefits to her and everyone else affected (Hansson, 2004). The choice between these standards raises basic issues in normative ethics that are too large to broach here. To simplify, 
I shall assume that the former, individual standard is the appropriate one in the contexts under discussion.

It should be clear, then, that the relevant question is not whether the mortality rates of kidney sales and dangerous employment are equal. The relevant question is much more complex: do the two options present comparable risk-benefit packages from an individual point of view? Once the issue is thus reframed, there appear to be both symmetries and asymmetries between selling a kidney and selling one's labour. Let us begin with the symmetries. On the benefit side both involve payment. And on the risk side both may lead to death and bodily harm. Just how symmetrical the options are in these two respects is difficult to say, and highly context-dependent, because both may involve very different levels of remuneration and harms of very different sorts and magnitudes. But there appears to be at least one systematic difference. Selling a kidney is necessarily harmful in the limited sense that even perfectly successful surgery causes some temporary pain and disability. By contrast, even very risky jobs are usually not harmful in any such certain and direct way, although there could perhaps be exceptions.

It might be thought that kidney vendors differ from employees in dangerous occupations because they know less about the health hazards they face. There is uncertainty about the long-term risks of a nephrectomy in the medical community (Glannon, 2008), an uncertainty that even the best-informed vendors would share. However, it is not unusual that people sign up for jobs with little knowledge or concern about the effects on their health twenty or thirty years later. Indeed, even those who care and seek information about such effects may (depending on the job) learn that there is little information to find. (Cf. Taylor, 2006, p. 138)

Beyond payment and risks of bodily harm, there seem to be clear asymmetries between kidney sales and hazardous occupations. Apart from providing income, employment 
typically gives people the opportunity to cultivate valuable, lasting relationships; selling a kidney presumably does not (NCB, 2011, p. 143). A related but even more important benefit that employment confers is social standing (Zutlevics, 2001, p. 298). The point here is not just that members of certain hazardous occupations, such as firefighters and policemen, are highly respected. The point is rather that having some job rather than none is likely to raise a person's status in the eyes of others and contribute to her own sense of self-worth. It is questionable whether kidney vendors can expect such benefits; indeed, empirical studies suggest that the opposite is the case. Iranian (Zargooshi, 2001) and Moldovan (ScheperHughes, 2003; Lundin, 2012) kidney vendors are reportedly heavily stigmatised and suffer deeply from shame, regret and self-reproach. The sale seems to erode rather than enhance their social status and sense of self-worth.

To the extent that bodily harm reduces a person's capacity to work, it may bring economic harm in its wake. Consequently, Iranian, Indian and Pakistani kidney vendors typically report a worsened economic situation after the sale - even taking into consideration the payment for the kidney (Zargooshi, 2001; Goyal et al., 2003; Naqvi et al., 2007). Of course, being injured at work may be economically just as devastating as suffering the harmful effects of a nephrectomy. But the potential economic harm is more systematic in the kidney sales case. One cannot sell a kidney without undergoing surgery, undergo surgery without needing recovery, or work while one recovers. It is difficult to think of jobs that inevitably impair a person's capacity to work for a comparable period of time.

\section{Regulation}

So once risks beyond mortality rates and benefits beyond payment are taken into account, kidney sales begin to look considerably less attractive than hazardous employment. There is, however, an obvious response to this concern: the risk-benefit profile of kidney sales is not 
immutable, but could be made more favourable through appropriate regulation. Indeed, one may add, hazardous employment is often an attractive option precisely because of similar regulation. Generally speaking, there are two regulative approaches: one may seek to either (i) lower the risks or minimise the harms to kidney vendors, or (ii) increase the benefits they receive. Let us look at each in turn.

Screening vendors carefully and guaranteeing adequate care during and after the operation would do much to lower the health risks they face. Such measures would also protect them from the negative economic effects of impaired work ability due to poor health. Of course, vendors would still not be capable of working during a limited period of recovery. But they need not suffer economically as a result if the payment is calculated so as to cover lost income and if they are guaranteed to continue their previous employment after recovery. While some of these measures seem unrealistic in developing countries, they may well be feasible in countries with high-quality health care and stringent labour legislation.

But can regulation be expected to protect kidney vendors from the harmful effects of stigmatisation? I am not so sure. These harms arise from deeply held and widely shared social norms and values, phenomena that are not easily shaped through regulation. Of course, it is reasonable to think that policy makers have some influence on social norms and values. But that influence is likely to be limited, long-term and somewhat unpredictable. To directly orchestrate swift changes of specific norms, such as those currently underlying stigmatisation of kidney vendors, seems like a rather ambitious feat. Unless regulators can achieve that feat, vendors would - initially at the very least - suffer shame and stigmatisation even in a legal, regulated kidney market.

The most obvious way of shifting the balance of risks and benefits to kidney vendors from the benefit side is to increase the amount of money they receive. It could be argued that even if selling a kidney is harmful or costly in ways that hazardous jobs are not, 
these disadvantages may be offset by larger payment. This suggestion raises the familiar and thorny problem of commensurability of value. ${ }^{\text {iii }}$ Are all harms and benefits reducible to the same "currency" of value and capable of being traded off against each other without loss? If we accept that risks are to be weighed against benefits we seem committed to a degree of commensurability. But we need not think that commensurability is total; we may hold that some goods can be weighed whereas others cannot.

It is notable that some commensurability is taken for granted in the employment context. It is considered appropriate, up to a point at least, that people run an elevated risk of physical harm at work if their salaries offer adequate compensation. But this is not to say that high salaries can compensate for everything. Can there be a high enough salary for (literally) licking other people's boots? We may want to distinguish between paying people to take physical risks and paying them to suffer degradation or humiliation. If we reason analogously about kidney sales, we may think that handsome payment can compensate vendors for health risks but not for shame and stigmatisation.

To sum up, the claim that kidney sales and hazardous employment involve comparable risks is far more difficult to sustain than it initially seemed. A convincing comparison would require taking into account the entire mix of harms, risks, benefits and chances that each option involves. This is a complex, largely empirical task. However, a brief review suggests that selling a kidney involves a less attractive balance of risks and benefits than selling one's labour, and it is not clear that regulation could change that. The analogy between the two is thus considerably weakened. It is perfectly consistent to permit risk taking in one context but not in the other if the risk-benefit profiles are different.

EQUAL RISK, EQUAL PERMISSIBILITY? 
Let us bracket the discussion in the previous section and assume, for the sake of argument, that the risk-benefit profile of kidney sales is indeed comparable to the risk-benefit profile of employment in, say, the mining, fishing or construction industry, or could easily be made comparable through appropriate regulation. Should we then conclude that kidney sales must be permitted because such employment is? While appealing at first glance, that conclusion would be much too quick.

Generally speaking, whether or not people are permitted to pursue different activities depends on different considerations, not only on how risky the activities are for them. Society might not let me drive without a seatbelt because I would unnecessarily risk harming or killing myself, while not letting me drive while intoxicated because I would risk harming or killing others. Thus understood, the seatbelt law is paternalistic; it restricts my freedom for my own good. By contrast, the drunk driving law restricts my freedom in order to protect others. Further, I may have my freedom restricted for other reasons than to protect my own or other people's welfare. For example, I may be denied the opportunity to drink in public because such behaviour is considered offensive. ${ }^{\text {iv }}$

When it is argued that the ban on kidney sales should be lifted because such sales are no riskier than certain occupations are, it is implicitly or explicitly assumed that the rationale for the ban is paternalistic. ${ }^{\mathrm{v}}$ That is, it is assumed that individuals are denied the opportunity to sell a kidney because doing so would be dangerous for them. But that assumption should not be taken at face value. We have seen that paternalism is just one among several different rationales for liberty-limiting policies, and even policies that appear paternalistic are sometimes better defended on other grounds (Feinberg, 1986). Let us briefly consider some possible non-paternalistic rationales for prohibiting kidney sales. 


\section{Protecting kidney recipients}

Payment for human body parts is routinely defended as a means to increasing their supply. The underlying assumption is that people are more likely to exchange body parts for money than to give them away for free. In The Gift Relationship, Richard Titmuss (1970) famously challenged that assumption, arguing that markets in blood were less rather than more efficient than systems relying on unpaid donation because they discouraged altruistically motivated donors. Analogous concerns have been raised about buying and selling other body parts, including kidneys (Zutlevics, 2001, p. 301; Rothman and Rothman, 2006). Insofar as such concerns can be given adequate empirical support (which arguably they currently lack; NCB, 2011), they provide a possible non-paternalistic rationale for banning kidney sales. If payment undermined altruistic donation to the extent of making fewer rather than more kidneys available, potential recipients would see their chances of receiving a kidney decrease. Were there reason to expect such effects, the ban could be defended as protecting recipients rather than vendors.

\section{Protecting societal values}

Titmuss not only believed that markets in blood discouraged altruistic donors, but also that they might weaken the general sense of fellow feeling between strangers that society needs to flourish (Titmuss, 1970; Archard, 2002). This reflects a more general, longstanding worry about the corrosive effects of markets on different values and relationships. ${ }^{\text {vi }}$ Many critics are unconvinced that markets have such effects (Mack, 1989; Wilkinson, 2003, pp. 109-116). Nonetheless, concerns about the erosion of values like altruism continue to shape policy debates about payment for kidneys and other body parts (NCB, 2011). Insofar as such concerns can be substantiated, they provide another non-paternalistic rationale for banning 
kidney sales: the point is not to protect individual vendors, but to preserve values and relationships that are (supposedly) good for all or most of us.

\section{Protecting individual third parties}

Harms to vendors, recipients and societal values aside, it has also been suggested that kidney sales might harm individual third parties. Lori Andrews raises the possibility that permitting such sales "could lead society to view poor people as suddenly having capital and consequently being ineligible for welfare benefits" (Andrews, 1986, p. 32). Similarly, Debra Satz (2010, pp. 200-201) argues that kidneys may become viewed as collateral if they are sold regularly enough, making loans more difficult to obtain for people unwilling to sell. In these cases, giving some people the opportunity to sell makes others worse off by changing their available options. Society may seek to block that opportunity in order to prevent such thirdparty harm - yet another non-paternalistic rationale.

My aim is not to determine how convincing these possible non-paternalistic rationales for banning kidney sales ultimately are. The point for the present discussion is that the analogy with hazardous employment does not work as an objection to them. The analogy seeks to show that it is not particularly harmful to sell a kidney, but that is irrelevant if the ban seeks to protect recipients, individual third parties or societal values instead of vendors. This is not to say that the analogy fails altogether, but simply that it can only hope to dismiss one sort of concern about kidney sales, namely paternalistic ones.

\section{KIDNEY SALES AND PATERNALISM}

The idea that people should not be free to sell a kidney because they might harm kidney recipients, third parties or societal values may seem unconvincing for two reasons. First, the 
arguments attempting to show that such harms would occur seem rather speculative. Second, even if such harms did in fact occur, it is not clear that they would be severe enough to outweigh the gains in liberty and wellbeing that permitting sales might bring. The idea of banning sales for paternalistic reasons - because they might harm vendors - may look more plausible. After all, the sale requires a healthy person to undergo invasive surgery, so there are tangible risks at stake. But here the analogy with hazardous employment suggests itself. If the paternalist accepts that people are allowed to take risky jobs for money, how could she consistently think that they should be denied to exchange a kidney for money, if the risks are no greater there? In this section I try to meet that challenge. I shall argue that even if the best rationale for banning kidney sales is paternalistic, and even if the risks of such sales are comparable (in the broad sense specified earlier) to the risks involved in hazardous but acceptable jobs, it does not follow that the ban cannot be consistently maintained. ${ }^{\text {vii }}$

A few words about paternalism are in order before proceeding further. A paternalistic action or policy interferes with a person's freedom in order to protect or promote her good or welfare. ${ }^{\text {vii }}$ The phrase "in order to" refers to the reason taken to justify the interference. An anti-smoking law restricts the freedom of smokers and advances their health. However, the law is not paternalistic if it seeks to protect non-smokers from passive smoking rather than protecting the smokers from themselves. It is the justification that makes an action or policy paternalistic, not its effects.

Following Joel Feinberg (1986), a distinction is commonly drawn between soft and hard paternalism. Soft paternalism interferes with substantially non-voluntary conduct. It either protects classes of people assumed on the whole to lack decisional capacity, or interferes with particular non-voluntary actions of otherwise competent people. Age limits on buying alcohol and tobacco are examples of the first kind of soft paternalism; stopping somebody from drinking a glass of poison that she mistakenly thinks is water is an example of 
the second kind. Hard paternalism, by contrast, interferes with substantially voluntary choices of competent people. Preventing a calm and mentally healthy adult from carrying out a carefully considered suicide plan is an example. The distinction between soft and hard paternalism obviously hinges on what counts as voluntary conduct. This is a contested question. However, lack of material information, incapacity or lack of opportunity to reason clearly about alternatives, internal compulsion, and coercive and manipulative external influences are usually assumed to make actions non-voluntary.

Hard paternalism is controversial because interfering with somebody's voluntary actions infringes her autonomy. Some believe that people's autonomy may never be set aside for their own good (Feinberg, 1986). Others think that hard paternalism can be justified when the infringement is small enough and the good at stake large enough (Arneson, 2005; Beauchamp and Childress, 2001). While not always unproblematic, soft paternalistic interference is much easier to justify because it involves no infringement of autonomy. Indeed, Feinberg argues that such interference is ultimately motivated by a concern for autonomy: "the soft paternalist's concern is not simply to prevent people from harming themselves...The defining purpose of the soft paternalist is to prevent people from suffering harm that they have not truly chosen to suffer or to risk suffering." (Feinberg, 1986, p. 119) This does not exclude entirely considerations of welfare, however. The riskier a course of action, the stronger the reason to interfere in order to make sure that it is really voluntary.

\section{Soft paternalism}

Assuming that the ban on kidney sales is best defended on paternalistic grounds, the first question to ask is whether it relies on soft or hard paternalism. Let us look at each in turn, beginning with soft paternalism - the more attractive alternative given the generally contentious status of hard paternalism. 
We have seen that soft paternalistic interference targets harmful actions that are substantially non-voluntary. So justifying the ban on kidney sales on soft paternalistic grounds requires showing that the potential vendors one seeks to protect would not sell their kidney voluntarily. Why wouldn't they? The answer typically proceeds from the assumption that vendors would be recruited among the very poor. They would be so desperate for money that they would have no other choice than to sell a kidney, the argument goes, and their choice would therefore be of questionable voluntariness (Audi, 1996, p. 145). There is a standard response to this standard concern: the lack of acceptable alternatives does not make someone's choice of the one alternative she has less voluntary (Wilkinson, 2003, p. 119; Taylor, 2005, p. 62; Radcliffe-Richards, 1996, p. 383). We do not think, for instance, that a patient cannot voluntarily consent to life saving surgery when the only other alternative is death (Wilkinson and Moore, 1997, p. 377). So why, it may be asked, should we think that a poor person's choice to sell a kidney is non-voluntary because she lacks better ways to reduce her poverty?

Proponents of kidney sales seem right to question the assumption that the poor cannot make voluntary and reasonable choices among the few options open to them. Nonetheless, I think that they dismiss concerns about poverty and voluntariness too quickly. Abject poverty does not as such make a person incapable of deciding for herself, but it does make her vulnerable to pressure from others. Evidence from both the illegal Indian and Pakistani kidney markets and the legal market in Iran suggests that vendors - who are invariably poor - are sometimes coerced or manipulated to sell by moneylenders, employers and families (Zaargoshi, 2001; Goyal et al., 2003; Naqvi et al., 2007). This should come as no surprise. Poverty creates pressure to provide others with money: one is likely to have debts to pay off, family members who are poorer still to provide for and so on. At the same time, poverty restricts the range of options available to raise that money. Together these factors 
make one susceptible to being pressured by others to pursue options one would not voluntarily seek out. Where available, selling a kidney may be one such option.

The soft paternalist may want to prohibit kidney sales in order to protect people from being pressured by others to sell against their will. It could be objected that all or even most vendors would not be under such pressure and that the ban therefore would interfere with voluntary choices as well (Taylor, 2005, pp. 61-62). This is true, but it does not undermine the soft paternalistic argument. The distinction between the justification of paternalistic policies and their effects is crucial here. Many paternalistic policies target groups containing both competent and incompetent decision-makers. In effect, they deny individuals who are capable of voluntarily deciding whether to make a potentially harmful choice the chance to do so. Nonetheless, they do not qualify as hard paternalism if the justification for interfering with these individuals is not to protect them, but instead to protect other members of the group from making the choice non-voluntarily. Such policies rely on a rationale that Franklin Miller and Alan Wertheimer (2007) call "group soft paternalism”. Consider their main example: the regulation of human subjects research. Potential subjects with sufficient knowledge and judgment to decide themselves the terms on which to participate in research (e.g. how large risks to take) are denied the chance to make such decisions - not for their own good, but as a consequence of protecting other subjects who lack these capacities.

A ban on kidney sales can be defended along analogous, group soft paternalistic lines (Malmqvist 2012). If a sufficiently large proportion of vendors are expected not to sell voluntarily, and if these vendors are not readily distinguished from other, autonomous ones, then there is reason to deny all who might consider selling kidney that opportunity. Here, too, the freedom of the whole group is restricted in order to protect an incompetent subset from harms they have not voluntarily chosen. 
It is crucial to note that the analogy with hazardous jobs has very limited force against a soft paternalistic ban on kidney sales. The essence of the analogy is the claim that the harmfulness of kidney sales is not large enough to warrant their prohibition. However, the soft paternalist does not seek to protect people from harm as such, but from harmful choices that are not truly theirs. What matters primarily is not how harmful an action is to the agent, but whether she incurs the harm voluntarily. ${ }^{\text {ix }}$ From this perspective, it is not inconsistent to permit people to choose risky occupations but not to make an equally risky choice of selling a kidney if the latter choice is more likely to be non-voluntary. And it does not seem far-fetched to think that it is. The instant reward from a kidney sale is likely a stronger incentive for thirdparty coercion than the delayed and typically gradual reward from a hazardous job.

\section{Hard paternalism}

The soft paternalistic argument for banning kidney sales is open to different objections (Malmqvist 2012). Would kidney vendors really be any more susceptible to impaired decision-making than people generally are when they sign up for risky jobs? Would it really be unfeasible to discriminate between vendors and interfere to protect the non-autonomous ones while letting the autonomous ones make their own decisions? Suppose that we find some such objection convincing and also that all non-paternalistic arguments fail. We still need not reject the ban on kidney sales. We could seek to justify the ban on hard rather than soft paternalistic grounds. The hard paternalistic rationale is not that vendors would risk harming themselves non-voluntarily, but that they would risk harm tout court.

Here, at last, it may seem that the analogy with hazardous jobs has a key role to play. If the hard paternalist thinks that employment in the mining, fishing or construction industry is not risky enough to warrant prohibition, and if the risks of kidney sales are no higher, how could she consistently think that such sales should remain prohibited? 
Voluntariness and effects on third parties aside, surely it must be the dangerousness of an activity to the agent that alone determines whether it should be permitted? Not quite.

Richard Arneson $(1997 ; 2005)$ has observed that hard paternalism gains attractiveness when seen from the point of view of distributive justice. Even among people capable of substantially voluntary choices there are large differences in decision-making ability. Due to variations in different cognitive faculties and emotional dispositions, some are better than others at looking after their own interests. Left to their own devices, Arneson notes, more able agents will tend to advance their own welfare more effectively whereas less able agents are more likely to pursue harmful or suboptimal options. Assuming that the more able agents tend to be better off already than the less able, it follows that "[a] ban on paternalism...gives to the haves and takes from the have-nots" (Arneson, 1997, p. 86). That is, collective anti-paternalism tends to increase inequalities of welfare. If equality of welfare matters morally, then, there tends to be a pro tanto reason in favour of paternalistic policies.

The upshot is that the strength of our reason for hard paternalistic interference not only depends on the magnitude of the harm the agent will incur if left unrestrained. It also depends on the agent's prior position on a welfare scale. Other things being equal, the worse off she is already the stronger the reason for preventing her from further worsening her situation.

This helps showing why the analogy with hazardous jobs is not a decisive objection even to a hard paternalistic ban on kidney sales. The hard paternalist who cares about equality holds that whether an activity should be permitted depends not only on how high are the risks it involves (relative to compensating benefits), but also on who would run these risks. Convincing her that kidney sales must be permitted because dangerous employment is requires showing not only that the risks involved are comparable, but also that kidney vendors and those engaged in such employment would be drawn from equally well off 
groups. But this latter assumption looks implausible. Even wholehearted kidney sales advocates believe that those most likely to sell a kidney would be the very poorest (Dworkin, 1994, p. 157; Taylor, 2005, p. 35), and evidence from existing kidney markets support that belief (Zargooshi, 2001; Naqvi, 2007). Dangerous but acceptable occupations are likely to attract people from more varied circumstances. Although this is a complex empirical question, my guess it that there is a systematic difference here. All jobs exclude some of the very worst off because they require some minimum skills and capacities. Kidney sales impose no such requirements and would thus remain an option even to those excluded from the labour market.

Until it is shown that kidney sales would not attract even worse off people than dangerous jobs do, hard paternalists may consistently stick to the ban on egalitarian grounds. Perhaps some hard paternalists remain unconvinced. Some who recognise the egalitarian pull of my argument might object that the risk that kidney sales harm some of the worst off is outweighed by the chance that they benefit others equally badly off. I am not against weighing; still, harms to the worst off should weigh more heavily than benefits of equal size to the equally badly off. Others might object that we should not care about equalising welfare, but instead resources or capabilities. But remember that welfare losses often overlap in practice with losses of these other goods. Hard paternalists of both varieties should, I think, agree with my main point: not only the dangerousness of kidney sales matters, but also who would sell. However, there is one last variety that may still disagree: hard paternalists indifferent to egalitarian justice. For them it is indeed the dangerousness of an activity to the agent that alone determines whether it should be permitted (barring effects on others). This is the only sort of paternalist opponent to kidney sales that the analogy with equally dangerous jobs can hope to convert.

\section{CONCLUSION}


If people may take significant risks for money by selling their labour, why not by selling parts of their bodies? The rhetorical force of this question is undeniable. However, I have suggested that it pulls very little weight as an argument for permitting kidney sales. First, on a sufficiently broad comparison it is not clear that the risks of selling a kidney are worth the benefits to the extent that occupational risks are worth the benefits. Nor is it clear that the two risk-benefit profiles could be made comparable through regulation. Second, and more importantly, even if they were comparable, it would not follow that kidney sales should be permitted because hazardous jobs are. Market opponents could want the ban to remain in place for non-paternalistic reasons: not to protect vendors, but instead to protect recipients, third parties or societal values. And paternalists, too, could consistently defend the ban even if such sales turned out to be no riskier than occupations that they find acceptable. Soft paternalists may want to protect would-be vendors from harms that they have not voluntarily chosen. Hard paternalists with egalitarian leanings may want to protect already badly off vendors from further worsening their situation. For neither species of paternalist is the size of the risk prevented all-important.

I conclude that the analogy between kidney sales and hazardous employment should be abandoned. Proponents of such sales are then deprived of one of their most common and intuitively appealing arguments. Of course, this does not settle the broader question whether legalising kidney sales is a justifiable policy all things considered. At the end of the day, perhaps people should be permitted to sell a kidney - but not because they are already permitted to sell their labour.

Acknowledgements: I thank Kalle Grill, Jurgen de Wispelaere and two anonymous reviewers for this journal for helpful comments. 
${ }^{\mathrm{i}}$ In addition to the authors already quoted, see Andrews (1986, p. 32), Dworkin (1994, p. 157), Harris (1998, p. 161), Radcliffe-Richards et al. (1998, p. 1951), Savulescu (2003, pp. 138-139), Wilkinson (2003, p. 108), Taylor (2005, ch. 6), Matas (2004, p. 2010) and Matas (2006, p. 1131).

ii The main exception is James Stacey Taylor (2005), who dedicates a whole chapter of his book Stakes and Kidneys: Why Markets in Human Body Parts are Morally Imperative to the analogy. For shorter but nonetheless useful discussions, see Audi (1996, pp. 143-146), Zutlevics (2001, pp. 298-299) and NCB (2011, pp. 142-143).

iii For more on incommensurability, see Chang (1997). My very rough characterisation of the problem differs from some of the characterisations in that volume, but should be suitable for the purposes of this paper.

${ }^{\text {iv }}$ I bring up seatbelt, drunk driving and public drunkenness laws to illustrate the point that liberty-limiting policies have different rationales. Whether actual such laws are or should be based on the rationales I attribute to them is not my present concern.

${ }^{\vee}$ Authors who explicitly make the connection to paternalism include Dworkin (1994, p. 157), Audi (1996, p. 143) and Taylor (2005, p. 119).

${ }^{\mathrm{vi}}$ For contemporary expressions of this old worry, see Radin (1996) and Satz (2010). vii A different, but structurally similar, challenge worth mentioning relies on an analogy with unpaid living donation rather than hazardous employment. If the paternalist thinks that people should be permitted to give up a kidney for free, how can she consistently deny that they should be permitted to do so for pay? After all, payment would not make the exchange any more dangerous. (Radcliffe-Richards, 1996, p. 386; Wilkinson, 2003, p. 108) A thorough discussion of this challenge would require another paper. Let me just note that paternalists could respond by employing the same strategies that I shall employ against the analogy with 
dangerous jobs. In brief, soft paternalists could argue that selling is more likely than donation to be non-voluntary, and egalitarian hard paternalists could argue that the risks of selling are likelier than the risks of donation to be borne by the worst off.

viii This rough characterisation is compatible with major more elaborate accounts of paternalism (Dworkin, 1972; Feinberg, 1986; Beauchamp and Childress, 2001).

ix I say "primarily" for two reasons. First, as pointed out above, soft paternalists hold that the dangerousness of a choice is indirectly relevant to whether it should be permitted in the sense that riskier choices require higher standards for ascertaining voluntariness. Second, group soft paternalist policies must justify interfering with both competent and incompetent agents. The restricted freedom suffered by competent agents is not justifiable by appealing to potential harms to them. However, it is justifiable by appealing to harms to other, incompetent agents and more so the greater these latter harms are. (For discussion, see Malmqvist 2012.) Nevertheless, voluntariness, not harm, remains of first importance. 


\section{REFERENCES}

Andrews, L. (1986) My Body, My Property. Hastings Center Report 16(5), 28-38.

Archard, D. (2002) Selling Yourself: Titmuss's Argument Against a Market in Blood. Journal of Ethics 6, 87-103.

Arneson, R.J. (1997) Paternalism, Utility, and Fairness. Reprinted in G. Dworkin (ed.), Mill's “On Liberty”: Critical Essays (pp. 83-114). Lanham, MD: Rowman \& Littlefield.

Arneson, R.J. (2005) Joel Feinberg and the Justification of Hard Paternalism. Legal Theory $11,259-284$.

Beauchamp, T.L. and Childress, J.F. (2001) Principles of Biomedical Ethics, $5^{\text {th }}$ ed. Oxford: Oxford University Press.

Audi, R. (1996) The Morality and Utility of Organ Transplantation. Utilitas 8, 141-158.

Bureau of Labor Statistics (BLS) (2011) National Census of Fatal Occupational Injuries in 2010 (Preliminary Results). Available online: www.bls.gov/news.release/pdf/cfoi.pdf

Cameron, J.S and Hoffenberg, R. (1999) The Ethics of Organ Transplantation Reconsidered: Paid Organ Donation and the Use of Executed Prisoners as Donors. Kidney International 55, 724-732.

Chang, R. (ed.) (1997) Incommensurability, Incomparability, and Practical Reason. Cambridge, Mass.: Harvard University Press.

Dworkin, G. (1972) Paternalism. Monist 56(1), 64-84.

Dworkin, G. (1994) Morality, Harm, and the Law. Boulder, CO: Westview.

Fabre, C. (2006) Whose Body is it Anyway? Justice and the Integrity of the Person. Oxford: Oxford University Press.

Feinberg, J. (1986) Harm to Self. New York: Oxford University Press.

Friedman, A.L. (2006) Payment for Living Organ Donation Should Be Legalised. British Medical Journal 333, 746-748. 
Glannon, W. (2008) Underestimating the Risk in Living Kidney Donation. Journal of Medical Ethics 34, 127-128.

Goyal, M., Mehta, R.L., Schneiderman, L.J. and Sehgal, A.R. (2002) Economic and Health Consequences of Selling a Kidney in India. Journal of the American Medical Association 288, 1589-1592.

Hansson, S.O. (2004) Weighing Risks and Benefits. Topoi 23, 145-152.

Harris, J. (1998) Clones, Genes, and Immortality: Ethics and the Genetic Revolution. Oxford: Oxford University Press.

Horrobin, S. (2005) Stakes and Ladders. Rejuvenation Research 8, 258-263.

Lundin, S. (2012) Organ Economy: Organ Trafficking in Moldova and Israel. Public Understanding of Science 21, 226-241.

Mack, E. (1989) Dominoes and the Fear of Commodification. In J.W Chapman and J.R. Pennock (eds.), Nomos XXXI: Markets and Justice. (pp. 198-225) New York: New York University Press.

Malmqvist, E. (2012) Are Bans on Kidney Sales Unjustifiably Paternalistic? Bioethics (early view, DOI: $10.1111 / \mathrm{j} .1467-8519.2012 .01984 . x)$

Matas, A.J., Bartlett, S.T., Leichtman, A.B. and Delmonico, F.L. (2003) Morbidity and Mortality after Living Kidney Donation, 1999-2001: Survey of United States Transplant Centers. American Journal of Transplantation 3, 830-834.

Matas, A.J. (2004) The Case for Living Kidney Sales: Rationale, Objections and Concerns. American Journal of Transplantation 4, 2007-2017.

Matas, A.J. (2006) Why We Should Develop a Regulated System of Kidney Sales: A Call for Action. Clinical Journal of the American Society of Nephrology 1, 1129-1132.

McNeill, P. (1997) Paying People to Participate in Research: Why Not? Bioethics 11, 390397. 
Miller, F.G. and Wertheimer, A. (2007) Facing Up to Paternalism in Research Ethics. Hastings Center Report 37(3), 24-34.

Naqvi, S.A.A. et al. (2007) A Socioeconomic Survey of Kidney Vendors in Pakistan. Transplant International 20, 934-939.

Nuffield Council on Bioethics (NCB) (2011) Human Bodies: Donation for Medicine and Research. London: Nuffield Council on Bioethics.

Radcliffe-Richards, J. (1996) Nephrarious Goings On: Kidney Sales and Moral Arguments. Journal of Medicine and Philosophy 21, 375-416.

Radcliffe-Richards, J. et al. (1998) The Case for Allowing Kidney Sales. Lancet 352, 19501952.

Radin, M.J. (1996) Contested Commodities: The Trouble With Trade in Sex, Body Parts, and Other Things. Cambridge, Mass.: Harvard University Press.

Rothman, S.M. and Rothman, D.J. (2006) The Hidden Cost of Organ Sale. American Journal of Transplantation 6, 1524-1528.

Satz, D. (2010) Why Some Things Should Not Be for Sale: The Moral Limits of Markets. Oxford: Oxford University Press.

Savulescu, J. (2003) Is the Sale of Body Parts Wrong? Journal of Medical Ethics 29, 138-139. Scheper-Hughes, N. (2003) Rotten Trade: Millennial Capitalism, Human Values and Global Justice in Organs Trafficking. Journal of Human Rights 2, 197-226.

Segev, D.L. et al. (2010) Perioperative Mortality and Long-term Survival Following Live Kidney Donation. Journal of the American Medical Association 303, 959-966.

Taylor, J.S. (2005) Stakes and Kidneys: Why Markets in Human Body Parts are Morally Imperative. Aldershot: Ashgate.

Titmuss, R.M. (1970) The Gift Relationship: From Human Blood to Social Policy. London: George Allen and Unwin. 
Wilkinson, S. (2003) Bodies for Sale: Ethics and Exploitation in the Human Body Trade. London: Routledge.

Wilkinson, M. and Moore, A. (1997) Inducement in Research. Bioethics 11, 373-389.

Zargooshi, J. (2001) Quality of Life of Iranian Kidney 'Donors'. Journal of Urology 166: 1790-1799.

Zutlevics, T.L. (2001) Markets and The Needy: Organ Sales or Aid? Journal of Applied Philosophy 18, 297-301. 